\section{Administration makes rings around congressional edict}

\section{Washington}

THE Reagan administration's Office of Management and Budget (OMB) has hatched what is being termed a "creative" scheme for undoing Congress's decision to increase the number of new research grants awarded by the National Institutes of Health (NIH).

Last year, Congress repeated its usual pattern of going one better than the administration in generosity toward NIH. It added some $\$ 580$ million to the Reagan request for $\$ 4,400$ million, already an alltime high. Along with the congressional pet projects $(\$ 5$ million for five new Alzheimer's disease centres, $\$ 10$ million for small universities and the historically black colleges, $\$ 34$ million for new clinical trials) there was an extra $\$ 280$ million for research project grants. The appropriations committees in both houses of Congress agreed that this money was for two purposes: increasing the size of each grant to the "historical level", and increasing the number of new and competing research grants each year to 6,500 .

The present 5,000-grant level, long an informal target for NIH, has more recently been effectively a ceiling. Congress was persuaded to increase the number of grants by testimony showing that many projects approved by study sections were neverthe-

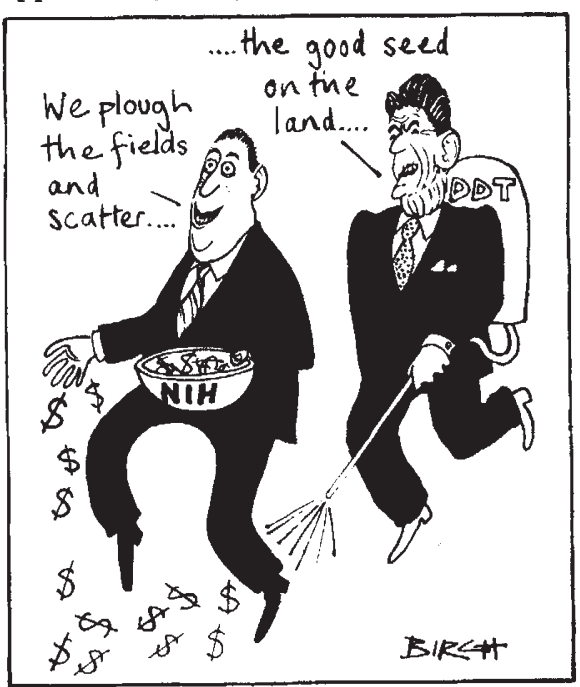

less not supported. The new money became available to NIH at the start of the present fiscal year, 1 October 1984.

The administration, however, wanted to keep the number of grants at 5,000 and OMB is apparently not taking no for an answer. In its hunt for cost-cutting measures to reduce the $\$ 200,000$ million annual federal deficit, OMB has singled out the projected growth of NIH grants. Because grants are awarded for three years, Congress's decision to raise the number of new grants to 6,500 per year would automatically require further budget jumps of some $\$ 300$ million for each of the next two years as well. The challenge for OMB was thus to devise some way of disposing of the money Congress had already appropriated for the current fiscal year that would not set a precedent for future increases.

The solution, undisguisedly contrived, may be difficult for Congress to challenge; OMB has ordered NIH to award only 5,000 new grants this year and has arranged that the extra cash will be set aside at once to cover the full three years of as many of those 5,000 grants as it takes to use up all the money (about 700 grants). Thus 4,300 grants have been appropriated funds for one year, according to OMB's reckoning, and 700 for all three years at once.

Congress usually appropriates only one year at a time; congressional staff members have already questioned the legality of OMB's action. But OMB may get its way. Congress's directive to increase the number
Space telescope

\section{Washington}

ASTRONOMERS with guaranteed observing time on the Hubble Space Telescope, as the Large Space Telescope is now called, met in Princeton last week to stake out their positions and concluded cooperative agreements dealing with everything from data sharing to press relations. The meeting, convened by John Bahcall, did not become the "bloodbath" some had feared, but, by eliminating duplication, increased observing opportunities. At a meeting the previous week in Tucson, astronomers had been divided over whether time allocated to guest observers should include large slots for "key projects".

Each of the seven guaranteed observer teams (one each for the six instruments plus one "observatory" team) has been assigned 400 hours of observing time by the National Aeronautics and Space Administration (NASA). Until the Princeton meeting, teams had jealously kept their plans secret from one another, but have now decided to "behave like gentlemen", according to Bahcall.

One problem is that immediate public recognition is likely for the first space telescope observations of such interesting objects as galaxy M-87, whether the hypothesized black hole is detected at its centre or not. In order to avoid rivalries, written agreements were signed to share press opportunities and to delay publication in academic journals until colleagues have of grants is not written into law, but appears only in the committee report. Such report language is considered indicative of congressional intent; legally, however, it is only part of the "legislative history" - the body of clarification that courts may look to in determining the intent of Congress. Congress has indeed taken such matters to the courts on occasion, but in this case, by the time the case could be heard, the fiscal year would probably be long gone.

OMB officials have revealed that the fiscal year 1986 budget request, to be released by the President this month, will also call for holding the line at 5,000 new grants. If Congress wants to be sure to have its generous way this time, it will probably have to write its intentions into law. But that is easier said than done: a multi-year effort to write new authorizing legislation for NIH ended in a presidential veto last fall because of administration and NIH opposition to its provisions, spelling out in detail the research missions of the various institutes and creating two new institutes that NIH did not want - one for arthritis and one for nursing. And putting the 6,500grant requirement into law would mean reopening all those issues, as well as some perennial Senate favourites, such as limitations on NIH-sponsored fetal research.

Stephen Budiansky

\title{
Users agree on inside track
}

seen results. Guaranteed observers' proposals, which will now be substantially reworked, will be formally submitted to NASA on 31 March.

In Tucson, six working groups reported on their deliberations on the desirability of key projects for up to 30 per cent of guest observer time. Although everyone accepts that some programmes will last longer than others, there were "spirited discussions" on how they should be designated and what they should be. While it seems that six key projects are now being considered, there is concern that the process should not prejudice new ideas. A meeting for potential European guest observers is to be held shortly in Munich; in the meantime, no final decisions on key projects have been reached, according to George Field of Harvard University, chairman of the space telescope advisory committee.

The telescope, which has been subject to several delays and cost overruns, is now being assembled by the Lockheed Corporation in Sunnyvale, California. Although it is scheduled for launch on the shuttle in August 1986, less optimistic observers, such as Richard Harms of Applied Research Corporation, who developed the faint object spectrograph on the telescope, doubt that the instrument will be ready in time. No outstanding technical problems are recognized, but, historically, problems do tend to surface during final assembly.

Tim Beardsley 